\title{
EKSISTENSI KOMUNIKASI EMPATI DALAM PENCEGAHAN PENUNTUTAN HUKUM PASIEN KEPADA DOKTER
}

\author{
Oleh : \\ Syahadah Siregar * \\ Abdul Halim Bin Ahmad*
}

\begin{abstract}
ABSTRAK
Seringkali dokter merasa sudah menjelaskan tentang penyakit ataupun tindakan medis yang akan dilakukan namun apa yang ingin disampaikan oleh dokter tidak sama dengan apa yang dipahami oleh pasien. Kesenjangan ini sangat berpengaruh pada penyelesaian masalah kesehatan pasien bahkan seringkali berlanjut pada penuntutan hukum terhadap dokter telah melakukan malpraktek dengan alasan pasien tidak puas atas kurangnya komunikasi tentang penyebab penyakit yang diderita sehingga pasien tidak siap dalam mengantisipasi resiko penyakit atau biaya perawatan medis. Salah satu factor penyebab lebih jelasnya adalah atribut kepribadian yang berhubungan dengan empati dan ketrampilan berkomunikasi seoranng dokter kepada pasien. Keterampilan berkomunikasi menimbulkan empati dari pasien sangat memberikan pengaruh memahami pasien secara menyeluruh, dokter akan dapat mendiagnosa penyakit pasien dengan lebih tepat dan menentukan pengobatan atau tindakan selanjutnya yang lebih tepat.
\end{abstract}

Kata Kunci: Eksistensi Komunikasi, Penuntutan Hukum, Pasien, Dosen

\section{A. Pendahuluan}

Undang-Undang RI No 36 Tahun 2009 tentang Kesehatan, pada pasal 5 disebutkan:

“(1) Setiap orang mempunyai hak yang sama dalam memperoleh akses atas sumber daya di bidang kesehatan.

(2) Setiap orang mempunyai hak dalam memperoleh pelayanan kesehatan yang aman, bermutu, dan terjangkau.

(3) Setiap orang berhak secara mandiri dan bertanggung jawab menentukan sendiri pelayanan kesehatan yang diperlukan bagi dirinya.”

dalam praktek sehari-hari seringkali dokter merasa sudah menjelaskan tentang penyakit ataupun tindakan medis yang akan dilakukan namun apa yang ingin disampaikan oleh dokter tidak sama dengan apa yang dipahami oleh pasien. Kesenjangan ini sangat berpengaruh pada penyelesaian masalah kesehatan pasien bahkan seringkali berlanjut pada tuntutan terhadap dokter.

\footnotetext{
* Mahasiswa Pada Program Doktoral Hukum Universiti Utara Malaysia.

* Pengajar Pada School of Law, Universiti Utara Malaysia.
} 
Fenomena yang terjadi maka pentingnya komunikasi antara pasien dengan. Semakin meningkatnya keinginan pasien agar Dokter lebih mendengarkan keluhan mereka bersamaan dengan meningkatnya biaya pengobatan, maka penelitian mengenai hubungan antara dokter pasien pada pelayanan kesehatan menjadi penting untuk diperhatikan bagi peneliti baik di bidang praktek maupun administrasi kesehatan.

Banyaknya tuduhan malpraktek yang dialamatkan kepada dokter akibat komunikasi yang tidak tepat. Sebagai badan yang mengawasi kode etik para dokter, Konsil Kedokteran Indonesia (KKI) merasa prihatin dengan masalah komunikasi dokter ini. Untuk itu KKI mengeluarkan buku "Manual Komunikasi Efektif" untuk memberikan rujukan bagi para dokter dalam mengasah kemampuan dalam berkomunikasi.

Untuk dapat menyampaikan tentang penyakit ataupun tindakan medis yang akan dilakukan agar dapat dipahami oleh pasien dibutuhkan kemampuan komunikasi yang baik . Komunikasi antara dokter dan pasien penting bagi pasien agar dapat menjaga kesehatan dirinya secara lebih baik ${ }^{1}$. Aplikasi definisi komunikasi dalam interaksi antara dokter dan pasien di tempat praktik diartikan tercapainya pengertian dan kesepakatan yang dibangun dokter bersama pasien pada setiap langkah penyelesaian masalah pasien. Ada empat langkah yang terangkum dalam satu kata untuk melakukan komunikasi, yaitu SAJI (Salam, Ajak bicara, Jelaskan, Ingatkan).

Rendahnya kepatuhan dalam mengikuti pengobatan merupakan masalah penting pada praktek kedokteran dan berhubungan juga dengan meningkatnya biaya pengobatan dan administrasi rumah sakit dan ini sangat menyulitkan bagi pelaku pelayanan kesehatan maupun dokter ${ }^{2}$. Ini memperlihatkan bahwa perilaku dokter terhadap pasien, kemampuan dalam menggali dan memahami kekhawatiran pasiennya, pemberian informasi yang tepat dan empati yang diperlihatkan akan membangun kepercayaan pasien dan kunci penentu dari kepatuhan terhadap pengobatan ${ }^{3}$

Dalam beberapa studi, komunikasi yang baik antara Dokter dan Pasien memperlihatkan dampak yang positif. Dalam studi digali mengenai efek dari proses dan hasil pelatihan ketrampilan komunikasi pada kepedulian terkait dengan tekanan emosi pasien $^{4}$.

\footnotetext{
${ }^{1}$ Street, R. M. 2009. Howdoes communication heal? Pathway linking clinician-patient communication to health outcomes. Patient Education Couns, hal. 74.

${ }^{2}$ Wong, S. Y. (March 2006, Vol 11 No 3). Communication Skill and Doctor-Patient Relationship.

${ }^{3}$ Wong, S. Y. (March,2006). Communication Skill and Doctor-Patient Relationship. Medical Buletin, Vol 11 No 3, hal. 7-9.

${ }^{4}$ Balint, E. (1969). The possibilities of patient-centred medicine. JR College Gen Pract.
} 
Efektifitas komunikasi antara dokter-pasien berhubungan dengan kepuasan pasien pada layanan kesehatan.

Penyuluhan dan pelatihan bagi para dokter di layanan primer untuk mengembangkan kemampuan komunikasi yang fokus pada pasien memberikan dampak yang positif bagi kepuasan pasien. Kepuasan pasien menjadi hal yang penting untuk diperhatikan karena ketidakpuasan pasien dapat menyebabkan tuntutan kepada dokter di layanan kesehatan ${ }^{5}$.

Walaupun banyak penekanan pada pentingnya komunikasi yang efektif dan hubungan dokter-pasien yang baik mempengaruhi kepuasan dan kesehatan, kepuasan dokter didalam pekerjaannya juga dapat menentukan bagusnya hubungan dokter-pasien Namun peneliti menduga bahwa adanya faktor ketiga yang mempengaruhi hubungan ini, yaitu atribut kepribadian yang berhubungan dengan empati dan ketrampilan berkomunikasi ${ }^{6}$.

Komunikasi psikososial pada kunjungan di ruang praktek dapat memperbaiki hasil akhir pasien dengan meningkatnya kepercayaan pasien terhadap dokternya. Hubungan antara pasien dan layanan kesehatan dimana pasien melihat adanya kepercayaan, kesetaraan dan dukungan yang tinggi dari dokter dalam terapi terkait dengan meningkatnya kepuasan pasien dan kepatuhan pada pengobatan.

Komunikasi efektif akan terjadi ketika dokter memiliki kemampuan empati yang baik dan empati itu sendiri dapat dikembangkan apabila dokter memiliki ketrampilan mendengar dan berbicara yang keduanya dapat dipelajari dan dilatih ${ }^{7}$. Tingkat empati manusia menjadi penting karena terkait dengan efektifitas waktu yang kemudian akan terkait dengan produktifitas.

\section{B. Faktor Komunikasi Menyebabkan Penuntutan Hukum Oleh Pasien Kepada Dokter}

Negara berkembang seperti Indonesia, di mana terdapat kesenjangan tingkat pendidikan, tingkat sosial dan tingkat ekonomi antara dokter dan pasien, menuntut peran aktif dokter baik sebagai pengirim maupun penerima pesan agar pesan yang ingin disampaikan dapat dipahami sesuai dengan yang dimaksud.

\footnotetext{
${ }^{5}$ Wong S. Y, Op.Cit

${ }^{6}$ Ibid

7 Parkin, T. (2011). Empathy: Its Significan and Monitoring Dietetic Consultation for Chronic Diseases Management. Plymouth: University Plymouth, School of Helth Profession.
} 
Melalui komunikasi antara dokter dan pasien yang dilatarbelakangi berbagai tingkat pendidikan, sosial, ekonomi maka diperlukannya ketrampilan komunikasi untuk dokter dalam menjalankan prakteknya. Namun pada sebagian besar dokter belum menyadari pentingnya aspek komunikasi sebagaimana aspek biomedis. Pada saat ini dunia kesehatan telah berubah arah dari model paternalistik dimana dokter meresepkan obat dan pasien menerima dengan pasrah menjadi model partisipasi dimana dokter dan pasien secara bersama memutuskan pengobatan yang akan dilakukan. Komunikasi antar dokter-pasien berhubungan dengan aspek psikologis dan sosial kesehatan masyarakat ${ }^{8}$.

Menurut Institute of Medicine (IOM) di Amerika Serikat, 100.000 orang terbunuh setiap tahunnya dan lebih dari setengah juta orang terluka akibat kelalaian dokter ataupun paramedis rumah sakit. Miskomunikasi menjadi penyebab utamanya selain kesalahan pada tindakan medis. Miskomunikasi dapat menyebabkan terjadinya kesalahan dalam pemeriksaan medis yang berakibat terjadinya kesalahan diagnosa dan pemberian resep. Keadaan ini dapat berakibat kematian pada pasien.

Didapat hubungan antara komunikasi yang tidak efektif dengan tuntutan hukum. Peningkatan kasus malpraktek banyak disebabkan karena ketidakmampuan dokter untuk dapat menjelaskan masalah sesuai dengan kemampuan pasien memahami masalah tersebut. Beberapa peneliti berteori bahwa komunikasi yang buruk antara dokter- pasien mereka mungkin menjadi penyebab utama dari malpraktek. Hubungan antara klaim malpraktek dan ketrampilan dokter berkomunikasi dinilai secara langsung, ada beberapa sumber barang bukti yang menjelaskan hubungan tersebut ${ }^{9}$.

Banyak laporan menyatakan bahwa keterampilan dokter dalam berkomunikasi tidak memadai, Waitzkin dalam penelitiannya menyimpulkan bahwa pasien menginginkan informasi lebih terperinci dari mereka dapatkan dari dokter. Waitzkin juga mebuktikan bahwa dokter kadang gagal mengatasi masalah pasien ketika mengabaikan keterangan pasien dan hanya berfokus pada riwayat penyakit. Demikian pula, Fadden dan rekan menemukan bahwa pasien lebih suka penjelasan lengkap terutama tentang risiko dan pilihan pada cara pengobatan. Gardner melaporkan bahwa paling sering dinyatakan bahwa tindakan malpraktek adalah ketika pasien 'tidak puas atas kurangnya komunikasi tentang

\footnotetext{
${ }^{8}$ Bensing, J. M. (1985). Doctor-Patient Communication and The Quality of Care; an obsevation study into affective and instrumental behavior in general practice. Tiburg: Erasmuis Universiteit Rotterdam.

${ }^{9}$ Golin, C. E., Thorpe, C., \& DiMatteo, M. R. (2002). Accessing the Patient's World:Patien-Physician Communication About Psycosocial Issues. Jones and Bartlett.
} 
penyebab penyakit yang diderita sehingga pasien tidak siap dalam mengantisipasi resiko penyakit atau biaya perawatan medis. ${ }^{10}$.

Bagaimana mencegah tuntutan hukum malpraktik terus menjadi perhatian penting bagi para dokter dan institusi kesehatan. Meskipun kompetensi profesional dalam praktek medis sangat penting, namun dari banyak penelitian menunjukkan bahwa kualitas medis perawatan kurang berkorelasi dengan terjadinya malpraktek. Data ini menunjukkan bahwa faktor-faktor lain yang terlibat dalam memicu mereka. Ada dua faktor risiko penting untuk terjadinya tuntutan hukum malpraktik yaitu "kualitas komunikasi" antara dokter-pasien dan persepsi bahwa dokter adalah sumber terjadinya kesalahan tersebut. Faktor-faktor ini dapat menimbulkan tuntutan pasien terhadap dokter, terlepas dari kompetensi dokter ${ }^{11}$.

Biaya yang berkaitan dengan kegiatan malpraktik medis di Amerika Serikat selama dekade terakhir telah menjadi masalah utama kebijakan kesehatan karena :

[1]. Sebagai akibat dari meningkatnya premi malpraktek di banyak daerah, menimbulkan kekurangan dokter dalam beberapa spesialisasi

[2], beberapa dokter enggan untuk melakukan prosedur berisiko tinggi, dan semakin banyak bukti dokter pensiun lebih awal. studi secara konsisten menemukan bahwa kualitas interaksi dokter-pasien merupakan faktor kunci dari keputusan pasien untuk menuntut dokter.

(3) Ketidak mampuan dokter dalam berkomunikasi efektif dengan pasien menyebabkan ketidak puasan dari pasien sehingga empati yang diharapkan untuk dapat menyelesaikan masalah kesehatan tidak tercapai. Kesenjangan pendidikan, sosial dan ekonomi antara dokter dan pasien berpengaruh pada tingkat empati antara dokter dan pasien.

Empati adalah komponen yang sangat penting dalam komunikasi yang terpusat pada pasien selain kemampuan dalam mendengar secara aktif dan kemampuan memdapat Empati menuntut dokter untuk tidak menghakimi dan dengan kemampuannya dapat memahami dan berkomunikasi dengan pasien dan memberi informasi ${ }^{12}$ (Parkin, 2011).

Penelitian saat ini menunjukkan bahwa ada hubungan antara empati dokter dan tingkat kepuasan pasien, baik kepuasan waktu dan biaya sehingga Pendidik, peneliti,

\footnotetext{
10 Adamson, T., Tschann, J., Gungllion, D., \& Oppenberg, A. (1989). Physician Communication Skills and Malpractice Claims: A Complex Relatiomship. West J Med, hal. 356-360

${ }^{11}$ Lester, W., \& Smith, S. (1993). Listening and Talking to Patients: A Remedy for Malpractice Suits? West J Med, hal. 268-272.

12 Parkin, Op.Cit
} 
dokter, dan pasien sering menganjurkan empati pada hubungan dokter-pasien. Namun, masih jarang penelitian yang dilakukan secara sistematis untuk meneliti bagaimana komunikasi dokter dengan pasien pada saat konsultasi dan bagaimana empati dokter pada saat pertemuan tersebut. Semakin positif tingkat empati yang diberikan dokter semakin respon yang diberikan oleh pasien, walaupun tidak ada hubungan antara intensitas emosional tingkat empati dalam tanggapan dokter berikutnya.

Pada tingkat yang lebih mendasar, tidak ada konsensus umum tentang makna empati. Beberapa telah menulis empati sebagai memiliki kognitif atau "role-taking" dimensi orang lain telah difokuskan pada dimensi afektif, kadang-kadang disebut "penularan emosi"; dan lainnya terfokus pada dimensi perilaku. Kemampuan perilaku sangat relevan dengan cara dokter mengkomunikasikan empati kepada pasien. Penelitian lebih lanjut harus memeriksa preferensi pasien dan hasil yang terkait dengan berbagai tingkat tanggapan empatik. Dengan demikian empati dapat dipandang sebagai elemen penting dari hubungan dokter-pasien. Dokter dan mahasiswa kedokteran diharapkan memiliki empati terhadap pasien mereka dan belajar keterampilan komunikasi empatik. Penelitian membuktikan bahwa tingkat empati dokter juga berpengaruh pada tingkat kepuasan pasien. Namun sangat sedikit diketahui bagaimana tingkat empati itu terjalin pada komunikasi dokter-pasien dalam praktek sehari-hari.

Kondisi diatas tentu tidak terlepas dari sistem pendidikan kedokteran selama ini. Pada awalnya mahasiswa kedokteran memulai pendidikan dengan tingkat empati yang tinggi terhadap orang lain, namun pada saat memasuki masa magang, empati tampaknya menurun selama proses magang. Hal ini disebabkan karena sistem pendidikan lebih mengutamakan ilmu dan biomedis dan masalah bukan menjadi tanggung jawab mahasiswa kedokteran ${ }^{13}$.

Hal ini menyatakan mahasiswa kedokteran dengan berbagai latar belakang budaya yang berbeda dan sebagian besar belum memikiki kematangan emosional untuk menanggapai terhadap kerentanan manusia dalam hal penyakit, cacat dan kematian secara universal, membuat pengetahuan tentang empati penting pada pendidikan kedokteran. Kemampuan berempati dalam berkomunikasi sangat penting dalam memberikan asuhan

13 Jo, L. D. (2007). Medical Student's view Regarding The Role Of Emphaty in Patient-Physician Interaction. Stillwater, Oklahoma: Oklahoma State University. 
keperawatan yang berkualitas tinggi kepada pasien dalam upaya untuk memahami pasien secara holistik ${ }^{14}$.

Ketidakpuasan pasien terhadap kinerja dokter sebagai salah satu tenaga medis dimana dokter tidak dapat menggali keluhan-keluhan pasien mengenai penyakit yang dideritanya menyebabkan kesalahan pemberian resep obat maupun tindakan sehingga memenuhi perbuatan mal praktek, maka hal inilah menimbulkan penuntutan hukum oleh pasien kepada dokter.

\section{Eksistensi Komunikasi Empati Mencegah Penuntutan Hukum Pasien Kepada Dokter.}

Dokter sebagai petugas pelayanan kesehatan harus dapat menggali permasalahan yang dihadapi oleh pasiennya terutama melalui komunikasi. Komunikasi empati akan membuat dokter untuk dapat lebih memahami keluhan pasien secara menyeluruh baik dari sisi biomedis maupun sisi psikososial. Dengan memahami pasien secara menyeluruh, dokter akan dapat mendiagnosa penyakit pasien dengan lebih tepat dan menentukan pengobatan atau tindakan selanjutnya yang lebih tepat. Ketepatan dalam mendiagnosa, menentukan pengobatan atau tindakan akan berdampak pada kesembuhan pasien dan efisiensi biaya yang harus dikeluarkan oleh pasien dan pada akhirnya akan memberikan kepuasan pada pasien.

Komunikasi yang dilakukan antara pasien dengan dokter ataupun sebaliknya meliputi Komunikasi umumnya adalah cara seseorang berbicara pada orang lain untuk menyampaikan informasi, pesan atau gagasan agar dapat dimengerti oleh kedua belah pihak. Cara ini dinamakan komunikasi verbal. Jika dengan cara komunikasi verbal, informasi, pesan atau gagasan belum juga dapat diterima oleh kedua belah pihak, maka dilakukan dengan cara nonverbal seperti menggunakan gerakan badan, tersenyum, menggeleng dan sebagainya.

Unsur yang paling penting dalam komunikasi bukan sekadar pada apa yang kita tulis atau kita katakan, tetapi lebih pada karakter kita dan bagaimana kita menyampaikan pesan kepada penerima pesan. Jika kata-kata atau pun tulisan kita dibangun dari teknik hubungan manusia yang dangkal (etika kepribadian), bukan dari diri kita yang paling dalam (etika karakter), maka orang lain akan melihat atau membaca sikap kita.

14 Libba R, M. (2007). Empathy and Empathic Communication : Nursing Student Perception of Program Effectiveness Academic Experience and Competence. Auburn: Auburn University. 
Syarat utama agar komunikasi itu efektif adalah kredibilitas. Keterampilan komunikasi antara perorangan adalah kemampuan untuk terus menerus membangun kredibilitas dan dapat dipercayanya segala apa yang kita komunikasikan. Untuk membangun kredibilitas harus ada isi pesan yang jelas, suara/intonasi dalam menyampaikan pesan dan wahana bagaimana orang itu menyampaikan pesan. Jadi semakin seseorang tidak konsekuen dengan ketiga hal tersebut, maka akan menentukan kredibilitas sesorang, semakin tidak konsekuen akan menjadi semakin "tidak dipercaya".

Dengan meningkatnya keinginan pasien agar Dokter lebih mendengarkan keluhan mereka bersamaan dengan meningkatnya biaya pengobatan, maka penelitian mengenai hubungan antara dokter pasien pada pelayanan kesehatan menjadi penting untuk diperhatikan bagi peneliti baik di bidang praktek maupun administrasi kesehatan.

Terbukti dengan komunikasi dokter-pasien yang lebih baik juga meningkatkan kesehatan secara fisik dan psikis, penemuan gejala, kepatuhan dalam kontrol pada penyakit kronis termasuk terkontrolnya tekanan darah, gula darah dan pengelolaan nyeri. Pada penelitian yang lebih baru, dipilih secara acak 39 Dokter keluarga dan 315 pasien didapatkan bahwa tingkat komunikasi yang berpihak pada pasien berhubungan dengan menurunnya ketidaknyamanan, berkurangnya kecemasan dan semakin baik mental pasien. Penelitian lainnya terkait pada gaya interaksi dokter terhadap pasien dan pendapat pasien terhadap mutu di layanan kesehatan, melalui metode cross-sectional yang dilakukan terhadap 2881 kunjungan pasien dari 138 dokter keluarga, didapat 4 kategori gaya dokter yaitu; fokus pada pasien, biopsikososial, biomedical dan dominasi dokter dengan memakai instrumen kesehatan dasar. Pada penelitian ini didapatkan bahwa dokter dengan gaya fokus berinteraksi dengan pasien dilaporkan memiliki kepedulian yang tertinggi terhadap pasien sebaliknya dokter dengan gaya dominasi pada dokter dilaporkan memiliki kepedulian terendah terhadap pasien.

Di dalam ilmu kedokteran ada dua pendekatan komunikasi yang dapat digunakan. Pertama "komunikasi berdasarkan kepentingan dokter dalam usaha menegakkan diagnosis, termasuk penyelidikan dan penalaran klinik mengenai tanda dan gejala-gejala", dan kedua "komunikasi berdasarkan apa yang dirasakan pasien tentang penyakitnya yang secara individu merupakan pengalaman unik. Di sini termasuk pendapat pasien, kekhawatirannya, harapannya, apa yang menjadi kepentingannya serta apa yang dipikirkannya". Dalam pemberian pelayanan medis kemampuan dokter berkomunikasi secara efektif dengan pasien merupakan kondisi yang diharapkan untuk dapat memberikan pengobatan yang 
tepat dan komunikasi yang efektif tidak memerlukan waktu yang lama. Komunikasi efektif terbukti memerlukan lebih sedikit waktu karena dokter terampil mengenali kebutuhan pasien (tidak hanya ingin sembuh). Memiliki kemampuan komunikasi yang baik sangat penting bagi seorang dokter untuk menjalin hubungan dengan pasien. Hubungan baik ini, memberikan pengaruh positif pada penurunan tingkat ketegangan emosional pasien, mengurangi ketidaknyamanan, ketidakpahaman dan pada akhirnya akan memperbaiki kesehatan mental pasien ${ }^{15}$.

Komunikasi yang baik juga akan meningkatkan kepuasan baik dokter maupun pasien sehingga pasien akan patuh dalam menjalankan pengobatan ${ }^{16}$. Hudgins (1982) menggunakan standar pada pelayanan rawat jalan dokter hanya membutuhkan waktu 15 menit untuk pasien baru dan 12 menit untuk pasien lama. Pentingnya komunikasi efektif ini juga dirasakan oleh Konsil Kedokteran Indonesia dengan membuat Manual Komunikasi Efektif Dokter-Pasien.

Permasalahan yang sering timbul dalam komunikasi antara dokter dan pasien $\operatorname{adalah}^{17}$ :

- Ketidakjelasan informasi ; interaksi antara dokter dengan pasien adalah sebuah proses yang komplek. Terjadinya miskomunikasi dapat berpotensi kesalahpahaman pada pengertian tentang prognosis, perawatan yang harus dilakukan, harapan hidup dan pengobatan yang harus dijalankan.

- Sikap tidak peduli dokter ; dokter menolak mendiskusikan perasaan dan dampak sosial dari keluhan pasien, sebab dapat menyebabkan penyesalan saat mereka tidak bisa mengatasinya atau dokter tidak punya waktu yang mencukupi.

- Kurangnya kerjasama antar dokter-pasien ; dokter tidak memberikan penjelasan atas informasi yang dibutuhkan oleh pasien agar pasien juga dapat membantu kesembuhan dirinya.

- Penolakan dari pasien ; saat ini pasien tidak lagi sebagai penerima informasi yang pasif. Pasien dapat secara aktif membandingkan informasi yang didapat dari dokter dengan sumber informasi ahli lainnya dan membandingkannya juga dengan apa yang dirasakan juga pengalaman dari lingkungan sekitarnya.

43.

${ }^{15}$ Fong Ha, J. L. (2010). Doctor-patient communication: A review. The Ochner Jurnal vol 10, hal. 38-

16 ibid
17 ibid 
Untuk mengatasi permasalah diatas dibutuhkan beberapa strategi yaitu, meningkatkan kemampuan dokter komunikasi dengan pelatihan komunikasi sehingga akan tercapai komunikasi dua arah antar dokter-pasien ${ }^{18}$. Dalam meningkatkan kemampuan komunikasi menekankan pada peran pasien dalam pengobatan, kepuasan pasien dan perbaikan mutu perawatan serta kesehatan. Pelatihan komunikasi, dokter dapat memahami bagaimana komunikasi dokter-pasien yang baik secara teori kemudian mempraktekannya dan menciptakan gayanya sendiri. Komunikasi dua arah memberikan kesempatan bagi dokter maupun pasien untuk saling memberi informasi dan secara bekerja sama untuk mencapai kesembuhan. Masih menurut (Fong Ha, 2010) dari komunikasi yang efektif antar dokter-pasien terbentuk pembicaran yang produktif dan menghasilkan kepercayaan pada keduanya.

Dokter dengan kemampuan komunikasi dan hubungan interpersonal yang baik akan dapat dengan lebih cepat mengetahui permasalahan, dapat dengan segera mengetahui keadaan krisis dan mendapat dukungan dari pasien yang dirawat. Menghasilkan mutu dan kepuasan yang lebih tinggi, biaya perawatan lebih murah dan yang terpenting pasien memahami tentang penyakitnya dan menjalankan pengobatan dengan patuh ${ }^{19}$

\section{Daftar Pustaka}

Adamson, T., Tschann, J., Gungllion, D., \& Oppenberg, A. Physician Communication Skills and Malpractice Claims: A Complex Relatiomship. West J Med, 1989.

Balint, E. The possibilities of patient-centred medicine. JR College Gen Pract, 1969.

Bensing, J. M. Doctor-Patient Communication and The Quality of Care; an obsevation study into affective and instrumental behavior in general practice. Erasmuis Universiteit Rotterdam, Tiburg, 1985.

Golin, C. E., Thorpe, C., \& DiMatteo, M. R. Accessing the Patient's World:PatienPhysician Communication About Psycosocial Issues. Jones and Bartlett, 2002.

Jo, L. D. Medical Student's view Regarding The Role Of Emphaty in Patient-Physician Interaction. Stillwater, Oklahoma State University, Oklahoma, 2007.

Libba R, M. Empathy and Empathic Communication : Nursing Student Perception of Program Effectiveness Academic Experience and Competence. Auburn University, Auburn, 2007.

Fong Ha, J. L. Doctor-patient communication: A review. The Ochner Jurnal vol 10, 2010.

Lester, W., \& Smith, S. Listening and Talking to Patients: A Remedy for Malpractice Suits? West J Med, 1993.

Parkin, T. Empathy: Its Significan and Monitoring Dietetic Consultation for Chronic Diseases Management, Plymouth: University Plymouth, School of Helth Profession, 2011.

\footnotetext{
18 ibid

${ }^{19}$ ibid
} 
Street, R. M. Howdoes communication heal? Pathway linking clinician-patient communication to health outcomes. Patient Education Couns, 2009.

Wong, S. Y. Communication Skill and Doctor-Patient Relationship. (March 2006, Vol 11 No 3).

Wong, S. Y. Communication Skill and Doctor-Patient Relationship. Medical Buletin, Vol 11 No 3, March, 2006. 